\title{
BMJ
}

\section{Impact of growth hormone therapy on adult height of children with idiopathic short stature: systematic review}

\author{
Annalisa Deodati, research fellow, Stefano Cianfarani, associate professor
}

\begin{abstract}
Molecular Endocrinology Unit-
DPUO, Bambino Gesù Children's

Hospital-"Rina Balducci" Center of

Pediatric Endocrinology, Tor

Vergata University, Rome, Italy

Correspondence to: S Cianfarani,

Department of Public Health and

Cell Biology, Tor Vergata University,

00133, Rome, Italy

stefano.cianfarani@uniroma2.it
\end{abstract}

Cite this as: BMJ 2011;342:C7157 doi:10.1136/bmi.c7157

\section{ABSTRACT \\ Objective To systematically determine the impact of growth hormone therapy on adult height of children with idiopathic short stature. \\ Design Systematic review. \\ Data sources Cochrane Central Register of Controlled Trials, Medline, and the bibliographic references from retrieved articles of randomised and non-randomised controlled trials from 1985 to April 2010.}

Data extraction Height in adulthood (standard deviation score) and overall gain in height (SD score) from baseline measurement in childhood.

Study selection Randomised and non-randomised controlled trials with height measurements for adults. Inclusion criteria were initial short stature (defined as height $>2$ SD score below the mean), peak growth hormone responses $>10 \mu \mathrm{g} / \mathrm{L}$, prepubertal stage, no previous growth hormone therapy, and no comorbid conditions that would impair growth. Adult height was considered achieved when growth rate was $<1.5 \mathrm{~cm} /$ year or bone age was 15 years in females and 16 years in males.

Results Three randomised controlled trials (115 children) met the inclusion criteria. The adult height of the growth hormone treated children exceeded that of the controls by 0.65 SD score (about $4 \mathrm{~cm}$ ). The mean height gain in treated children was 1.2 SD score compared with 0.34 SD score in untreated children. A slight difference of about $1.2 \mathrm{~cm}$ in adult height was observed between the two growth hormone dose regimens. In the seven nonrandomised controlled trials the adult height of the growth hormone treated group exceeded that of the controls by 0.45 SD score (about $3 \mathrm{~cm}$ ).

Conclusions Growth hormone therapy in children with idiopathic short stature seems to be effective in partially reducing the deficit in height as adults, although the magnitude of effectiveness is on average less than that achieved in other conditions for which growth hormone is licensed. The individual response to therapy is highly variable, and additional studies are needed to identify the responders.

\section{INTRODUCTION}

Short stature is the commonest cause of referral to a paediatric endocrine unit. Although several conditions can lead to impaired linear growth, most short children do not fit into any clearly defined category and are referred to as having idiopathic short stature. Idiopathic short stature is considered present when height is more than 2 standard deviations below the corresponding mean height for a given age, sex, and population group, without evidence of systemic, endocrine, nutritional, or chromosomal abnormalities. ${ }^{1}$ According to this definition, most children referred for short stature will be classed as having idiopathic short stature at the end of the diagnostic investigation. ${ }^{2}$

In 2003, growth hormone therapy was approved in the United States for children with idiopathic short stature with height at or greater than 2.25 standard deviations (1.2 centiles) below the mean for age and sex, associated with growth rates unlikely to permit attainment of adult height in the normal range, and in whom diagnostic evaluation excluded other causes for short stature that should be observed or treated by other means. Recently, a consensus statement of the International Societies of Pediatric Endocrinology and the Growth Hormone Research Society proposed that children with idiopathic short stature whose heights were less than $-2.0 \mathrm{SD}$ scores and who were more than 2.0 SD scores below their mid-parental target height or had a predicted height less than -2.0 SD scores warranted consideration for treatment. ${ }^{3}$ However, although growth hormone therapy increases growth rate in the first years of treatment, controversy continues over its use for the treatment of idiopathic short stature and how much additional height may be gained. ${ }^{4}$ Available data are affected by several biases. Firstly, idiopathic short stature is a heterogeneous condition that includes normal variants of growth, such as familial short stature and constitutional delay of growth and puberty, characterised by the achievement of an adult height within the range of mid-parental height. Secondly, a wide variety of dosages has been used in the different studies. Thirdly, trials have been carried out in relatively small study cohorts often not followed up to the achievement of adult height. Owing to these uncertainties, the European Agency for the Evaluation of Medicinal Products Europe has not yet approved the use of growth hormone in children with idiopathic short stature. Since the last Cochrane review, ${ }^{5}$ results from further long term trials have been published, prompting pharmaceutical companies 


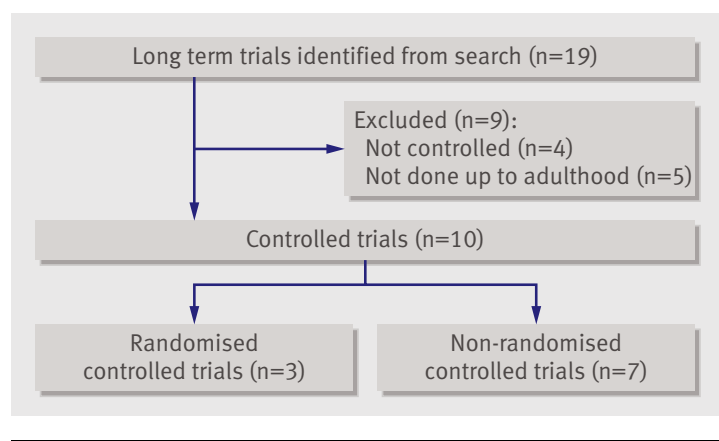

Fig 1| Search strategy for selection of trials

to reiterate their applications and raising the debate on the need for European approval even in the lay public.

We examined the evidence that long term growth hormone treatment in children with idiopathic short stature may improve their height as adults. We carried out a systematic review of all randomised and non-randomised controlled trials of growth hormone use in children with idiopathic short stature published up to April 2010.

\section{METHODS}

We searched the Cochrane Central Register of Controlled Trials, Medline, and the bibliographic references from all retrieved articles describing such trials up to April 2010 using the search terms "growth hormone" and "final height" and "adult height" and "idiopathic short stature". No language restrictions were applied.

Inclusion criteria were initial short stature, defined as height more than $2 \mathrm{SD}$ scores below the mean; peak growth hormone responses greater than $10 \mu \mathrm{g} / \mathrm{L}$; prepubertal stage; no previous growth hormone therapy; and no comorbid conditions that would impair growth, such as chromosomal abnormalities, bone diseases, chronic diseases interfering with growth, treatment with steroids or sex steroids, and dysmorphic syndromes. Adult height was considered achieved when growth rate was $<1.5 \mathrm{~cm} /$ year or bone age was 15 years in females and 16 years in males.

\section{Efficacy outcome measures and quality assessment}

The primary efficacy outcome measure was the difference in adult height between treated and untreated children. We considered a mean difference in adult height of more than $0.9 \mathrm{SD}$ scores (about $6 \mathrm{~cm}$ ) as a satisfactory response to growth hormone therapy. This value was chosen as it represents the mean difference in adult height between growth hormone treated and untreated children born small for gestational age. ${ }^{6}$ The SD score, also called $\mathrm{z}$ score, represents the distance between the raw score and the population mean in units of the standard deviation. We calculated the SD score with the formula: $\mathrm{SD}$ score $=(\mathrm{x}$-average $\mathrm{x}) /$ $\mathrm{SD}$, where $\mathrm{x}$ is the observed measurement, average $\mathrm{x}$ is the mean of this measurement at the relevant age, and $\mathrm{SD}$ is the standard deviation from the mean. The SD score is negative when the raw score is below the mean and positive when above.

Secondary efficacy outcome measures were height gain from inclusion in the study to adulthood (at least $\geq 1$ SD score) and difference between adult height and mid-parental height (at least $\geq 1 \mathrm{SD}$ score). None of the studies provided raw data on single participants, therefore in the analysis we considered the average values for height (SD score) at start of therapy and in adulthood and their standard deviations.

Randomised controlled trials allow decision makers to draw causal inferences linking interventions and outcomes with protection against bias. Therefore randomised controlled trials begin with a "high quality" rating. The strength of a recommendation reflects the degree of confidence that the desirable effects of a recommendation outweigh the undesirable effects. Desirable effects can include beneficial health outcome, less burden, and cost savings. Undesirable effects can include harms, more burden (that is, patient compliance), and expenses.

According to the Endocrine Society, ${ }^{7}$ a scientific trial should be evaluated and classified into one of two grades (strong and weak) of recommendation and the quality of the evidence into one of four categories (high, moderate, low, and very low). On this basis a grading was assigned to each of the three randomised controlled trials.

\section{Statistical analysis}

For primary analysis we calculated the effect size for each randomised controlled trial. The effect size was computed as the mean difference (treated minus untreated) and the changes (adult height minus baseline height) for each trial. We present these scores in a paired analysis with their $95 \%$ confidence intervals. Then we calculated the global effect size, pooling the data. When the effect size was significant in a fixed model we repeated the analyses using a random effects model. ${ }^{8}$ The random effects model incorporates statistical heterogeneity (results, methods, and publication bias) and provides a more conservative estimate of the pooled effect size than a fixed model. We calculated $\mathrm{I}^{2}$ values for quantifying heterogeneity in the meta-analysis. $\mathrm{I}^{2}$ describes the percentage of variability in point estimates that is due to heterogeneity rather than to sampling error. Although no universal rule covers the definitions of mild, moderate, or severe heterogeneity, $\mathrm{I}^{2}$ values more than $50 \%$ indicate notable heterogeneity, whereas values less than $30 \%$ indicate mild heterogeneity. We assessed publication bias by funnel plot analysis (see web extras). As the significance of the effect size may be affected by a single trial, we carried out a sensitivity analysis. When trials presented enrolling biases, we excluded these studies from the analysis to verify whether the same trend was observed with the remaining trials. Analyses for randomised controlled trials were carried out using Review Manager 5 software for Windows package (Nordic Cochrane Centre, Copenhagen, Denmark). 
Table 1 |Characteristics, results, and quality grading of randomised controlled trials of growth hormone therapy in children with idiopathic short stature

\begin{tabular}{|c|c|c|c|c|c|c|c|c|c|}
\hline Study and group & No & $\begin{array}{c}\text { Mean (SD) age } \\
\text { at start of therapy } \\
\text { (years) }\end{array}$ & $\begin{array}{c}\text { Growth } \\
\text { hormone dose } \\
(\mathrm{mg} / \mathrm{kg} / \text { day })\end{array}$ & $\begin{array}{c}\text { Mean (SD) years } \\
\text { of therapy }\end{array}$ & $\begin{array}{l}\text { Mean (SD) height } \\
\text { at baseline } \\
\text { (SD score) }\end{array}$ & $\begin{array}{l}\text { Mean (SD) } \\
\text { adult height } \\
\text { (SD score) }\end{array}$ & $\begin{array}{l}\text { Mean (SD) } \\
\text { height gain } \\
\text { (SD score) }\end{array}$ & $\begin{array}{l}\text { Difference (cases } \\
\text {-controls) in adult } \\
\text { height (SD score) }\end{array}$ & Quality \\
\hline \multicolumn{10}{|l|}{ McCaughey et al $1998^{9}$ : } \\
\hline Treated & 8 & $6.24(0.38)$ & 0.04 & 6.2 (range $5.5-6.5$ ) & $-2.52(0.26)$ & $-1.14(1.06)$ & $1.38(0.7)$ & 1.23 & \multirow{2}{*}{ Low } \\
\hline Untreated & 6 & $6.14(0.62)$ & - & - & $-2.55(0.32)$ & $-2.37(0.46)$ & $0.18(0.4)$ & - & \\
\hline \multicolumn{10}{|l|}{ Leschek et al $2004^{10 *}$ : } \\
\hline Treated & 22 & $12.5(1.6)$ & 0.03 & $4.4(1.6)$ & $-2.7(0.6)$ & $-1.77(0.80)$ & $0.93(0.75)$ & 0.57 & \multirow{2}{*}{ Moderate } \\
\hline Untreated & 11 & $12.9(1.1)$ & - & $4.1(1.7)$ & $-2.8(0.6)$ & $-2.34(0.56)$ & $0.46(0.23)$ & - & \\
\hline \multicolumn{10}{|c|}{ Albertsson-Wikland et al $2008^{11}$ : } \\
\hline Treated & 49 & $11.5(1.3)$ & 0.033 to 0.067 & $5.64(1.37)$ & $-2.84(0.56)$ & $-1.6(0.68)$ & $1.24(0.82)$ & 0.6 & \multirow{4}{*}{ Moderate } \\
\hline $0.033 \mathrm{mg} / \mathrm{kg} / \mathrm{day}$ & 18 & $11.5(1.3)$ & 0.033 & - & - & $-1.7(0.68)$ & $1.20(0.82)$ & 0.5 & \\
\hline $0.067 \mathrm{mg} / \mathrm{kg} /$ day & 31 & - & 0.067 & - & - & $-1.5(0.84)$ & $1.30(0.73)$ & 0.7 & \\
\hline Untreated & 19 & $12(1.6)$ & - & - & $-2.76(0.39)$ & $-2.2(0.75)$ & $0.40(0.62)$ & - & \\
\hline
\end{tabular}

\section{RESULTS}

The search strategy identified 19 long term studies (>3 years). Nine studies were excluded; five were not carried out up to adulthood and four were not controlled trials. Three ${ }^{9-11}$ of the 19 studies ${ }^{12-22}$ were randomised controlled trials, the remainder non-randomised controlled trials (fig 1). Only one study included a placebo control group. ${ }^{10}$

\section{Randomised controlled trials}

The three randomised controlled trials (115 children, 79 cases and 36 controls) were of low or moderate quality (table 1). Little or no information was available on the method of randomisation. If the treated group of a single study contained subgroups, the group and its subgroups were analysed separately. In one trial ${ }^{11}$ the children were subdivided according to dose of growth hormone $(0.033$ and $0.067 \mathrm{mg} / \mathrm{kg} /$ day).

Children were enrolled in the randomised controlled trials if their SD score for height was below -2.0. The mean chronological age at start of therapy ranged from 6.1 to 12.9 years (mean age 10.2 (SD 1.1) years for all children, 10.08 (SD 1.09) years for treated children, and 10.04 (SD 1.1) years for untreated children). All the children were prepubertal, the daily dose of growth hormone ranged from 0.033 to $0.067 \mathrm{mg} / \mathrm{kg}$, the mean duration of therapy was 5.4 (SD 1.5) years, and the mean height was -2.7 (SD 0.45) SD score (-2.72 (SD $0.5) \mathrm{SD}$ score for treated children and -2.7 (SD 0.43) SD score for untreated children).

\section{Non-randomised controlled trials}

Seven non-randomised controlled trials (477 children, 181 cases and 296 controls) were assessed (table 2). The inclusion criteria for these trials were similar. The mean chronological age at start of therapy ranged from 7.6 to 12.5 years (mean age 10.7 (SD 1.9) years for all children, 10.6 (SD 1.9) years for treated children, and 10.7 (SD 1.9) years for untreated children). All the children were prepubertal. The dose of growth hormone ranged from 0.02 to $0.05 \mathrm{mg} / \mathrm{kg} / \mathrm{day}$, the mean duration of therapy was 5.3 (SD 1.8) years, and the mean initial height was -2.8 (SD 0.5): -2.9 (SD 0.6) for treated children and -2.7 (SD 0.5) for untreated children.

\section{Randomised controlled trials Adult height}

In one of the randomised controlled trials, children with a baseline SD score for height of -2.5 and treated for about 6.2 years achieved an average near final height of -1.1 SD score compared with -2.4 SD score in untreated children (fig 2). ${ }^{9}$ In the only double blind and placebo controlled trial, treated children achieved an average adult height of -1.77 SD score compared with -2.34 SD score in untreated children. ${ }^{10}$ Treated children in the remaining study ${ }^{11}$ achieved a mean SD score for adult height of -1.6 compared with -2.2 in untreated children. This trial reported two subgroups of children treated according to two growth hormone dose regimens (table 1). The children treated with a daily dose of $0.067 \mathrm{mg} / \mathrm{kg}$ achieved a mean adult height of -1.5 SD score compared with -1.7 SD score for children treated with $0.033 \mathrm{mg} / \mathrm{kg} /$ day, corresponding to a mean difference of $2 \mathrm{~cm}$.

The mean adult height derived from the three randomised controlled trials was -1.52 SD score for treated children and -2.30 SD score for untreated children. The adult height achieved by those in the treated group significantly exceeded that of the controls, with a mean difference of $0.65 \mathrm{SD}$ score (about $4 \mathrm{~cm}$ ) $(95 \%$ confidence interval 0.40 to $0.91 ; \mathrm{P}<0.001$, fig 2 ). See web extra supplemental data 1 for the results of the analysis carried out according to a fixed model. After exclusion of a trial with the greater enrolment bias, the same trend was observed with the remaining trials (see web extra supplemental data 11).

In two of the studies ${ }^{910}$ the difference in SD score for adult height was $1.23(7.4 \mathrm{~cm})$ and $0.57(3.4 \mathrm{~cm})$, respectively. In the third study ${ }^{11}$ the overall difference was $0.6 \mathrm{SD}$ score $(3.6 \mathrm{~cm})$. The difference in adult height between treated and untreated children was $0.5 \mathrm{SD}$ score $(3 \mathrm{~cm})$ in those receiving growth hormone 
Table 2 |Characteristics, results, and quality grading of non-randomised controlled trials of growth hormone therapy in children with idiopathic short stature

\begin{tabular}{|c|c|c|c|c|c|c|c|c|c|}
\hline Study and group & No & $\begin{array}{l}\text { Mean (SD) age } \\
\text { at start of } \\
\text { therapy (years) }\end{array}$ & $\begin{array}{c}\text { Dose } \\
\text { (mg/kg/day) }\end{array}$ & $\begin{array}{l}\text { Years of } \\
\text { therapy }\end{array}$ & $\begin{array}{l}\text { Mean (SD) height at } \\
\text { baseline (SD score) }\end{array}$ & $\begin{array}{l}\text { Mean (SD) } \\
\text { adult height } \\
\text { (SD score) }\end{array}$ & $\begin{array}{c}\text { Mean (SD) } \\
\text { height gain (SD } \\
\text { score) }\end{array}$ & $\begin{array}{l}\text { Difference (cases } \\
\text {-controls) in adult } \\
\text { height (SD score) }\end{array}$ & Quality \\
\hline \multicolumn{10}{|l|}{ Wit et al $1995^{12}$ : } \\
\hline Treated & 12 & $9.2(1.6)$ & 0.02 & 5.7 & $-3.8(0.7)$ & $-2.4(0.9)$ & $1.4(0.9)$ & 0 & \multirow{2}{*}{ Low } \\
\hline Untreated & 27 & $10.5(1.2)$ & - & - & $-3.2(0.3)$ & $-2.4(0.7)$ & $0.8(0.5)$ & - & \\
\hline \multicolumn{10}{|c|}{ Hindmarsh et al $1996^{13}$ : } \\
\hline Treated & 16 & 8.35 (1.88) & 0.02 to 0.04 & 7.5 & $-2.17(0.58)$ & $-1.33(0.94)$ & $0.84(0.76)$ & 0.55 & \multirow{2}{*}{ Low } \\
\hline Untreated & 10 & $7.62(1.50)$ & - & - & $-2.34(0.61)$ & $-1.88(0.57)$ & $0.46(0.6)$ & - & \\
\hline \multicolumn{10}{|c|}{ Lopez-Siguero et al $1996^{14}$ : } \\
\hline Treated & 20 & $11.4(1.3)$ & 0.02 to 0.03 & 5.3 & $-2.8(0.52)$ & $-1.46(0.7)$ & $1.34(0.55)$ & 0.55 & \multirow{2}{*}{ Low } \\
\hline Untreated & 44 & $10.7(2.2)$ & - & - & $-2.38(0.4)$ & $-2.01(0.7)$ & $0.37(0.6)$ & - & \\
\hline \multicolumn{10}{|c|}{ Buchlis et al $1998^{15}$ : } \\
\hline Treated & 36 & $11.9(2.8)$ & 0.04 & 3.5 & $-2.9(0.6)$ & $-1.5(0.8)$ & $1.4(0.7)$ & 0.6 & \multirow{2}{*}{ Low } \\
\hline Untreated & 58 & $12.5(2.5)$ & - & - & $-2.9(0.7)$ & $-2.1(1.0)$ & $0.8(0.8)$ & - & \\
\hline \multicolumn{10}{|c|}{ Lopez-Siguero et al $2000^{16}$ : } \\
\hline Treated & 35 & $11.1(1.4)$ & 0.02 & 5.3 & $-2.78(0.5)$ & $-1.31(0.7)$ & $1.47(0.6)$ & 0.72 & \multirow{2}{*}{ Low } \\
\hline Untreated & 42 & $10.8(2.2)$ & - & - & $-2.4(0.4)$ & $-2.03(0.7)$ & $0.37(0.8)$ & - & \\
\hline \multicolumn{10}{|c|}{ Coutant et al $2001^{17}$ : } \\
\hline Treated & 32 & $11.7(2.0)$ & 0.02 & $3.9(1.8)$ & $-3.0(0.67)$ & $-2.1(0.76)$ & $0.9(0.57)$ & 0.02 & \multirow{2}{*}{ Low } \\
\hline Untreated & 51 & $12.1(2.8)$ & - & - & $-2.74(0.64)$ & $-2.08(1.01)$ & $0.66(0.89)$ & - & \\
\hline \multicolumn{10}{|l|}{ Wit et al $2002^{18}$ : } \\
\hline \multirow[t]{3}{*}{ Treated } & 30 & $10.7(2.2)$ & 0.03 to 0.04 & 5.9 & $-3.3(0.5)$ & $-1.9(0.9)$ & $1.4(0.9)$ & 0.5 & Low-moderate \\
\hline & 18 & $10.7(2.2)$ & 0.03 & - & - & $-2.4(1.0)$ & $0.9(1.0)$ & 0 & Low-moderate \\
\hline & 12 & $10.7(2.2)$ & 0.04 & - & - & $-1.3(0.7)$ & $2(0.8)$ & 1.1 & Low-moderate \\
\hline Untreated & 64 & $10.9(1.1)$ & - & - & $-3(0.5)$ & $-2.4(0.8)$ & $0.6(0.6)$ & - & \\
\hline \multicolumn{10}{|c|}{ Wit et al $2002^{18}$ : subgroups } \\
\hline \multicolumn{10}{|c|}{ Familial short stature: } \\
\hline Treated & 5 & $10.2(1.8)$ & 0.03 to 0.04 & 5.9 & $-3.2(0.5)$ & $-2.1(1.0)$ & $1.1(0.6)$ & 0.1 & \\
\hline Untreated & 10 & $10.9(1.1)$ & - & - & $-3(0.5)$ & $-2.2(0.9)$ & $0.8(0.5)$ & - & \\
\hline \multicolumn{10}{|c|}{ Non-familial short stature: } \\
\hline Treated & 36 & $10.7(2.2)$ & 0.02 to 0.04 & 5.9 & $-3.2(0.5)$ & $-2.0(1.0)$ & $1.2(0.8)$ & 0.4 & \\
\hline Untreated & 45 & $10.9(1.1)$ & - & - & $-3(0.5)$ & $-2.4(0.8)$ & $0.6(0.6)$ & - & \\
\hline
\end{tabular}

$0.033 \mathrm{mg} / \mathrm{kg} /$ day and $0.7 \mathrm{SD}$ score $(4.2 \mathrm{~cm})$ in those receiving $0.067 \mathrm{mg} / \mathrm{kg} /$ day.

In two of the studies ${ }^{910}$ the difference between adult or near final height and baseline predicted height in children treated with growth hormone increased by $3.5 \mathrm{~cm}$ and $0.32 \mathrm{SD}$ scores, respectively.

\section{Height gain}

In one study the mean height gain in treated children was $1.38 \mathrm{SD}$ score $(8.28 \mathrm{~cm})$ compared with $0.18 \mathrm{SD}$ score $(1.08 \mathrm{~cm})$ in untreated children (fig 2). ${ }^{9}$ In the second study the mean height gain was $0.93 \mathrm{SD}$ score $(5.58 \mathrm{~cm})$ in treated children compared with $0.46 \mathrm{SD}$ score $(2.76 \mathrm{~cm})$ in untreated children. ${ }^{10}$ In the remaining study the overall mean height gain was $1.24 \mathrm{SD}$ score $(7.44 \mathrm{~cm})$ in treated children compared with $0.40 \mathrm{SD}$ score $(2.4 \mathrm{~cm})$ in untreated children. ${ }^{11}$ The mean height gain in children treated with growth hormone $0.033 \mathrm{mg} / \mathrm{kg} /$ day was $1.2 \mathrm{SD}$ score $(7.2 \mathrm{~cm})$ compared with $1.3 \mathrm{SD}$ score $(7.8 \mathrm{~cm})$ in those treated with the higher dose of $0.067 \mathrm{mg} / \mathrm{kg} /$ day.

The mean height gain from the three studies was 1.20 SD score $(7.2 \mathrm{~cm})$ in treated children and 0.34 SD score $(2.0 \mathrm{~cm})$ in untreated children (fig 2). The height gain achieved by the treated group significantly exceeded that of controls, with a mean difference of 0.79 SD score $(4.7 \mathrm{~cm})(95 \%$ confidence interval 0.50 to $1.09 ; \mathrm{P}<0.001$, fig 2). See web extra supplemental data 2 for the results of the analysis done according to a fixed model.

\section{Adult height corrected for mid-parental height}

Only two studies reported mid-parental height (fig 3). In one of the studies mean adult height corrected for midparental height was $-0.66 \mathrm{SD}$ score in treated children compared with -1.02 SD score in untreated children. ${ }^{10}$ In the other study, ${ }^{11}$ mean adult height corrected for mid-parental height was $-0.1 \mathrm{SD}$ score in children treated with growth hormone $0.033 \mathrm{mg} / \mathrm{kg} /$ day and $0.4 \mathrm{SD}$ score in those treated with $0.067 \mathrm{mg} / \mathrm{kg} /$ day compared with $-1.0 \mathrm{SD}$ score in untreated children. The overall mean corrected adult height from the two studies was -0.4 SD score in treated children and $-1.01 \mathrm{SD}$ score in untreated children. The mean corrected adult height achieved by the treated group significantly exceeded that of the controls, with a mean difference of $0.87 \mathrm{SD}$ score $(95 \%$ confidence interval 0.28 to $1.46, \mathrm{P}=0.004$, fig 3). See web extra supplemental data 3 for the results of the analysis carried out according to a fixed model. 


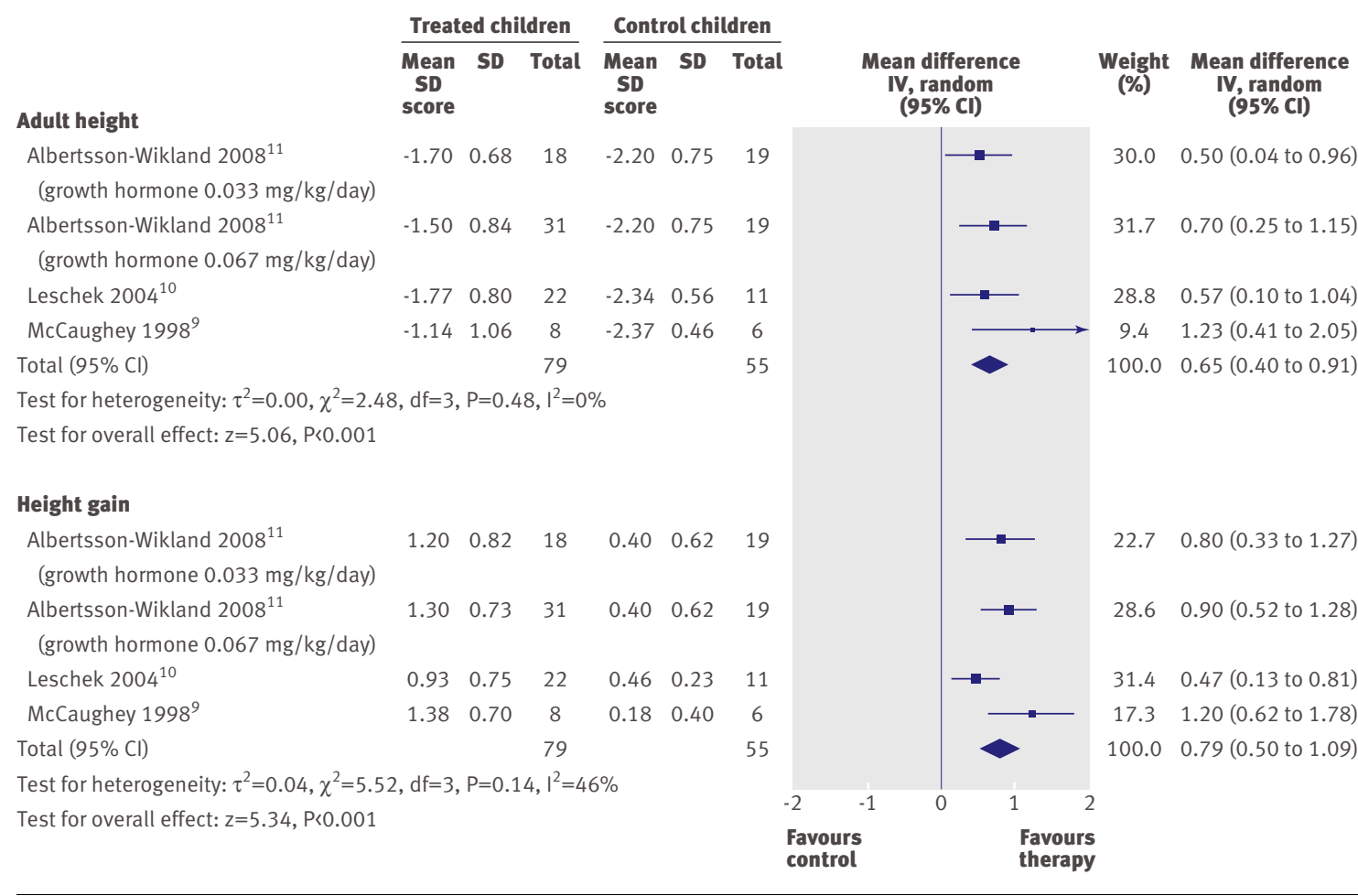

Fig 2 | Effect of long term growth hormone therapy at conventional doses on adult height and height gain in randomised controlled trials. Results of meta-analysis according to random model

\section{Non-randomised controlled trials Adult height}

The mean adult height derived from the seven non-randomised controlled trials was -1.7 SD score for treated children and -2.1 SD score for untreated children (table 2 and fig 4). The adult height achieved by the treated group significantly exceeded that of the controls, with a mean difference of $0.45 \mathrm{SD}$ score $(3 \mathrm{~cm})(95 \%$ confidence interval 0.18 to $0.73, \mathrm{P}=0.001$, fig 4$)$. See web extra supplemental data 4 for the results of the analysis carried out according to a fixed model.

In one study the difference in adult height between treated and untreated children was $0.5 \mathrm{SD}$ score $(3 \mathrm{~cm}) .{ }^{18}$ The difference in adult height between treated and untreated children was 0 SD score in those treated with growth hormone $0.03 \mathrm{mg} / \mathrm{kg} /$ day compared with $1.1 \mathrm{SD}$ score $(6.6 \mathrm{~cm})$ in those treated with $0.04 \mathrm{mg} / \mathrm{kg} / \mathrm{day}$.

\section{Height gain}

In one study, mean height gain in treated children was 1.4 SD score $(8.4 \mathrm{~cm})$ compared with $0.6 \mathrm{SD}$ score $(3.6 \mathrm{~cm})$ in untreated children. ${ }^{18}$ The mean height gain in children treated with growth hormone $0.03 \mathrm{mg} / \mathrm{kg} /$ day was $0.9 \mathrm{SD}$ score $(5.4 \mathrm{~cm})$ compared with $2.0 \mathrm{SD}$ score $(12 \mathrm{~cm})$ in those treated with $0.04 \mathrm{mg} / \mathrm{kg} / \mathrm{day}$.

Overall, the mean height gain from the seven nonrandomised controlled trials was $1.28 \mathrm{SD}$ score $(8 \mathrm{~cm})$ in the treated children and 0.6 SD score $(4 \mathrm{~cm})$ in the untreated children (fig 4).
The height gain achieved by the treated group significantly exceeded that of the controls, with a mean difference of $0.71 \mathrm{SD}$ score $(5 \mathrm{~cm})$ (95\% confidence interval 0.42 to $0.99, \mathrm{P}<0.001$, fig 4 ). See web extra supplemental data 5 for the results of the analysis carried out according to a fixed model.

\section{Quality of evidence and strength of recommendation}

The quality score for two of the trials ${ }^{1011}$ denoted moderate quality evidence. The first study ${ }^{10}$ was the only available randomised double blind placebo controlled trial. However, the proportion of dropouts was high; $40 \%$ in the growth hormone treated group and 65\% in the placebo group. Adult height was measured in six children in the treated cohort and only three in the placebo cohort. The other study ${ }^{11}$ lacked detail on the randomisation procedure. The whole study population comprised only 68 children: 19 controls and 49 treated children (18 with low dose and 31 with high dose growth hormone). Finally, in the second of these two trials, ${ }^{11}$ results were affected by a high variability. The remaining trial ${ }^{9}$ was classed as of low quality evidence because the study population was small (seven treated and six randomised untreated girls), no power calculation was described, and the authors reported the achievement of near final height in both treated and untreated groups.

The difference in adult height between treated and untreated children was considered as the primary efficacy outcome measure. A mean difference in adult height of more than 0.9 SD score (about $6 \mathrm{~cm}$ ) was considered as a satisfactory response to growth 


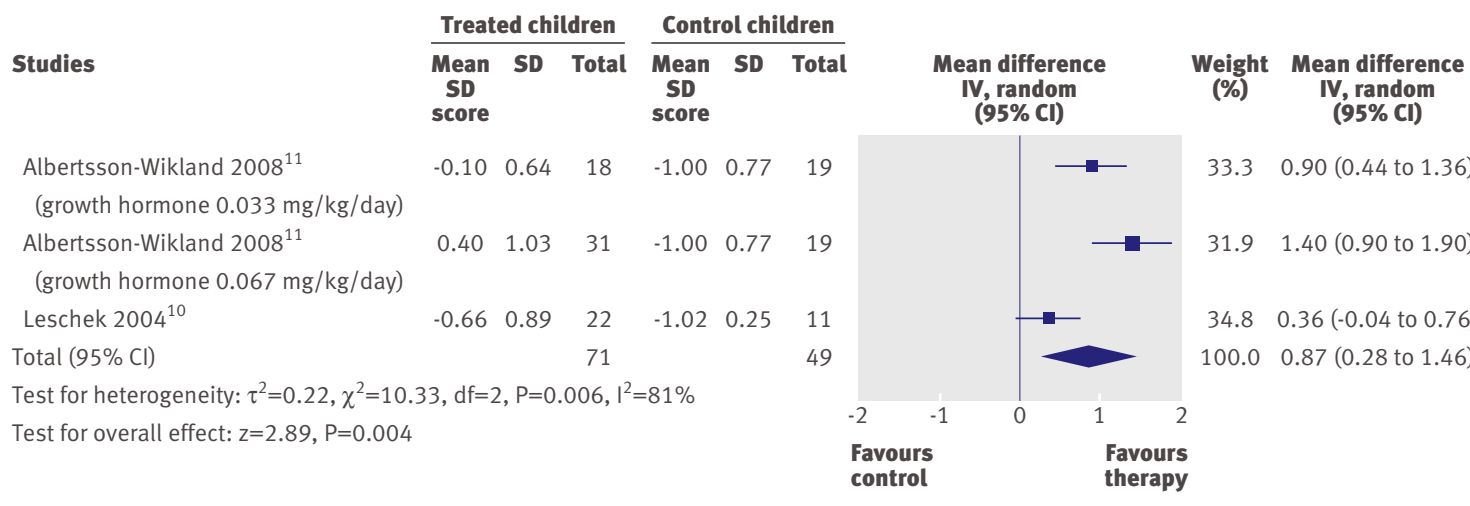

Fig 3 | Effect of long term growth hormone therapy at conventional doses on adult height corrected for mid-parental height in randomised controlled trials. Results of meta-analysis according to random model

hormone therapy. Although arbitrary and flawed this represents an acceptable cut-off value for determining the minimum "desirable effect" of long term growth hormone therapy, representing the mean difference in adult height between treated and untreated children in another already approved indication for growth hormone in non-growth hormone deficient children, such as born small for gestational age. The gain in SD score between height at inclusion and adult height (at least $\geq 1$ SD score) and difference between adult height and mid-parental height (at least -1 SD score or more), were considered as secondary efficacy outcome measures. According to these variables, a weak recommendation was assigned to all three randomised controlled trials because none achieved the established goals. Only in the high dose group of the study by Albertsson-Wikland et al, ${ }^{11}$ the adult height corrected for midparental height of treated children was 1.4 SD score.

Low quality evidence and a weak recommendation were assigned to the non-randomised controlled trials with the exception of one study, ${ }^{18}$ which was of lowmoderate quality as the two groups of treated children were randomised (table 2). This study is, however, affected by the extreme variability of results.

\section{Predictors of adult height}

A wide individual variability in the response to growth hormone therapy was reported in all the studies. Multiple linear regression analyses were used to construct the best model for predicting adult height SD score. The major predictors of adult height reported so far were early age at start of therapy, dose of growth hormone, length at birth, difference between height and mid-parental height, and delay in bone age. ${ }^{23}$

\section{DISCUSSION}

In this systematic review of 19 trials reporting the long term effect of growth hormone therapy in children with idiopathic short stature only three were randomised controlled trials carried out up to adulthood. To date no single high quality evidence randomised controlled trial has been carried out up to the achievement of adult height. Considering the two best quality studies, the average adult height achieved by treated children exceeded that of untreated controls, from 0.57 to 0.70 SD score $(3.4-4.2 \mathrm{~cm})$. One systematic review ${ }^{5}$ assessed the effects of growth hormone therapy on both short term and long term growth in children with idiopathic short stature. However, this systematic review did not consider the outcome measures analytically, did not evaluate and classify the trials according to the quality of evidence and strength of recommendation, and is not up to date as new long term trials have recently been published.

The weight of the evidence, although affected by the lack of studies with high quality and strong recommendation, indicates that growth hormone therapy increases adult height in children with idiopathic short stature. However, the growth promoting effect of growth hormone therapy is small, and data analysis shows wide individual variability, which may partly be related to the heterogeneity of the study population.

One randomised controlled trial ${ }^{11}$ and non-randomised controlled trial ${ }^{18}$ reported a dose dependent effect of growth hormone therapy on adult height. However, only the non-randomised controlled trial showed a difference in adult height between untreated children and children treated with high dose growth hormone of more than $0.9 \mathrm{SD}$ score.

\section{Limitations of the review}

One potential limitation of any meta-analysis is the pooling of studies with heterogeneous populations. However, the rigorous entry criteria and review procedures for the current analyses were instituted to exclude studies in patients with known causes of short stature. A second potential limitation involves the effect of study dropouts on the validity of study findings. A third confounder is the small sample size, with its high chance of false positive results. A fourth potential limitation of any meta-analysis is the "file-drawer" effect, in which studies with negative results might remain unpublished thus biasing the literature towards positive findings.

\section{Implications for clinicians and policymakers}

Our results may have potential implications for clinical practice and health policy. Much of the debate about use 
of growth hormone in children with idiopathic short stature has centered on the magnitude of growth hormone effect on adult height. The current findings, although based on only three randomised controlled trials, indicate that long term growth hormone therapy can partially reduce the height deficit of children with idiopathic short stature, but the mean difference between treated and untreated children is 0.65 SD score (about 4 $\mathrm{cm}$ ). These results suggest that the debate should shift to whether the gain in adult height is of sufficient clinical importance and value to warrant widespread treatment of children with idiopathic short stature.

Practitioners and policy makers need to address the clinical importance and value of the height gained in relation to the goals of treatment. Consideration of additional factors will be important for deciding whether growth hormone should be used in children with idiopathic short stature in practice, including the impact of the height gained on physical and psychosocial wellbeing, adverse effects, cost of therapy, and patients' expectations. Although an economic analysis is beyond the scope of this article, the cost-benefit ratio has repeatedly been considered for growth hormone therapy. Here we report that the mean final difference in adult height between treated and untreated children with idiopathic short stature is about $4 \mathrm{~cm}$ after 5.4 years of growth hormone therapy. Therefore, the average annual cost of growth hormone therapy is about $€ 20000$ $(£ 17000, \$ 27000)$ per year of treatment, which corresponds to about $€ 27000$ per gained centimetre. In other already approved non-classical indications of growth hormone therapy, such as small for gestational age and Turner syndrome, the reported mean difference in adult height between treated and untreated children is about $6 \mathrm{~cm}$ and $7 \mathrm{~cm}$, respectively. ${ }^{624}$

\section{Potential harms of growth hormone therapy}

None of the included studies reported serious adverse effects of growth hormone therapy. A decreased sensitivity to insulin (as fasting hyperinsulinaemia, increased fasting glucose, and reduced tolerance during oral glucose tolerance test) has been described. All the effects were reversible after discontinuation of therapy. However, metabolic memory could predispose these people to long term increased risk of type 2 diabetes. Occasionally, a dose dependent increase of insulin-like growth factor-I concentrations reaching values above $3 \mathrm{SD}$ score was reported. ${ }^{11}$ Although evidence is lacking for an increased risk of malignancy, the mitogenic and antiapoptotic actions of insulin-like growth

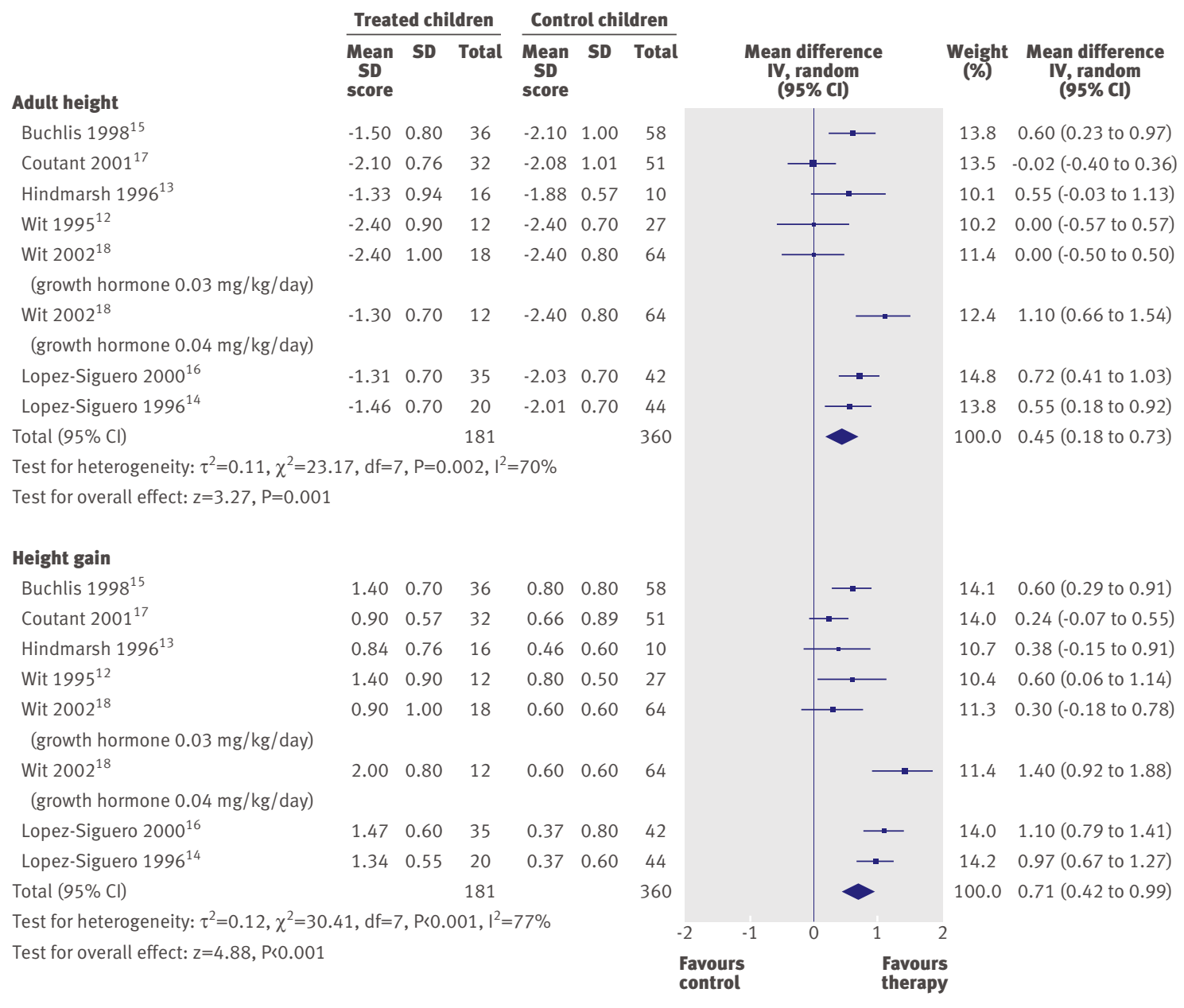

Fig 4 Effect of long term growth hormone therapy on adult height and height gain in non-randomised controlled trials. Results of meta-analysis according to random model 


\section{WHAT IS ALREADY KNOWN ON THIS TOPIC}

Growth hormone therapy has been approved in the United States for children with idiopathic short stature

A consensus statement proposed that children with height below -2.0 SD score and more than 2.0 SD score below their midparental target height warrant consideration for treatment

\section{WHAT THIS STUDY ADDS}

The magnitude of effect of growth hormone in reducing the adult height deficit is on average less than that achieved in other conditions for which growth hormone is licensed, increasing adult height by about $4 \mathrm{~cm}$

To date no study has fulfilled the evidence based medicine criteria for high quality of evidence and strong recommendation

The individual response to therapy is highly variable, and further studies are needed to identify the responders guidelines for the diagnosis and treatment of children with idiopathic short stature: a summary statement of the growth hormone research society in association with the Lawson Wilkins Pediatric Endocrine Society and the European Society for Pediatric Endocrinology. J Clin Endocrinol Metab 2008;93:4210-7.

4 Finkelstein BS, Imperiale TF, Speroff T, Marrero U, Radcliffe DJ, Cuttler L. Effect of growth hormone therapy on height in children with idiopathic short stature: a meta-analysis. Arch Pediatr Adolesc Med 2002;156:230-40.

5 Bryant J, Baxter L, Cave CB, Milne R. Recombinant growth hormone for idiopathic short stature in children and adolescents (review). Cochrane Database Syst Rev 2007;18:1-35.

6 Maiorana A, Cianfarani S. Impact of growth hormone therapy on adult height of children born small for gestational age. Pediatrics 2009;125:e537-46.

7 Swiglo BA, Murad MH, Schunemann HJ, Kunz R, Vigersky RA, Guyatt GA, et al. A case for clarity, consistency, and helpfulness: state-of-the-art clinical practice guidelines in endocrinology using the grading of recommendations, assessment, development, and evaluation system. J Clin Endocrinol Metab 2008;93:666-73.

8 Hedges LV, Pigott TD. The power of statistical tests in meta-analysis. Psychol Methods 2001;6:203-21.

9 McCaughey ES, Mulligan J, Voss LD, Betts PR. Randomized trial of growth hormone in short normal girls. Lancet 1998;351:940-4

10 Leschek EW, Rose SR, Yanovski JA, Troendle JF, Quigley CA, Chipman JJ, et al. Effect of growth hormone treatment on adult height in peripubertal children with idiopathic short stature: a randomized, doubleblind, placebo-controlled trial. J Clin Endocrinol Metab 2004;89:3140-8.

11 Albertsson-Wikland K, Aronson AS, Gustafsson J, Hagenäs L, Ivarsson SA, Jonsson B, et al. Dose-dependent effect of growth hormone on final height in children with short stature without growth hormone deficiency. J Clin Endocrinol Metab 2008;93:4342-50.

12 Wit IM, Boersma B, de Muinck Keizer-Schrama SM, Nienhuis HE, Oostdijk W, Otten BJ, et al. Long-term results of growth hormone therapy in children with short stature, subnormal growth rate and normal growth hormone response to secretagogues. Clin Endocrinol 1995;42:365-72.

13 Hindmarsh PC, Brook CGD. Final height of short normal children treated with growth hormone. Lancet 1996;348:13-6.

14 Lopez-Siguero JP, Martinez-Aedo MJ, Moreno-Molina JA. Final heigh after growth hormone therapy in children with idiopathic short stature and a subnormal growth rate. Acta Pediatr 1996;85:113-47.

15 Buchlis JG, Irizarry L, Crotzer BC, Shine BJ, Allen L, MacGillivray MH. Comparison of final heights of growth hormone-treated vs untreated children with idiopathic growth failure. J Clin Endocrinol Metab 1998;83:1075-9.

16 Lopez-Siguero JP, Garcia-Garcia E, Carralero I, Martinez-Aedo MJ. Adult height in children with idiopathic short stature treated with growth hormone. I Pediatr Endocrinol Metab 2000;13:1595-602.

17 Coutant R, Rouleau S, Despert F, Magontier N, Loisel D, Limal JM. Growth and adult height in GH-treated children with nonacquired $\mathrm{GH}$ deficiency and idiopathic short stature: the influence of pituitary magnetic resonance imaging findings. J Clin Endocrinol Metab 2001;86:4649-54

18 Wit JM, Rekers-Mombarg LT, Dutch Growth Hormone Advisory Group. Final height gain by GH therapy in children with idiopathic short stature is dose dependent. J Clin Endocrinol Metab 2002;87:604-11.

19 Wit J-M, Rekers-Mombarg LT, Cutler GB, Crowe B, Beck TJ, Roberts K, et al. Growth hormone (GH) treatment to final height in children with idiopathic short stature: evidence for a dose effect. J Pediatr 2005;146:45-53.

20 Schmitt K, Bluemel P, Waldhor T, Lassi M, Tulzer G, Frisch H. Shortand long-term (final height) data in children with normal variant short stature treated with growth hormone. Eur J Pediatr 1997;156:680-3.

21 Bernasconi S, Street ME, Volta C, Mazzardo G. Final height in nongrowth hormone deficient children treated with growth hormone. The Italian multicenter study group. Clin Endocrinol 1997;47:261-6.

22 Loche S, Cambiaso P, Setzu S, Carta D, Marini R, Cappa M. Final height after growth hormone therapy in non-growth-hormonedeficient children with short stature. J Pediatr 1994;125:196-200.

23 Ranke MB, Lindberg A, Price DA, Darendeliler F, Albertsson-Wikland K, Wilton P, et al. Age at growth hormone therapy start and first-year responsiveness to growth hormone are major determinants of height outcome in idiopathic short stature. Horm Res 2007;68:53-62.

24 Baxter L, Bryant J, Cave CB, Milne R. Recombinant growth hormone for children and adolescents with Turner syndrome. Cochrane Database Syst Rev 2007;1:CD003887.

25 Allen DB. Growth hormone post-marketing surveillance: safety, sales, and the unfinished task ahead. J Clin Endocrinol Metab 2010;95:52-5.

Accepted: 10 November 2010 stature. Summary. Horm Res 1996;45(suppl 2):64-6S

2 Wit JM, Clayton PE, Rogol AD, Savage MO, Saenger PH, Cohen P. evaluation. Growth Horm IGF Res 2008;18:89-110.

3 Cohen P, Rogol A, Deal C, Saenger P, Reiter E, Chernausek S, et al on behalf the 2007 ISS Consensus Workshop participants. Consensus 